\title{
A FURTHER NOTE ON THE RELATION BETWEEN VARIOUS ATMOSPHERIC CONDITIONS AND THE OCCUR- RENCE OF CEREBRAL HÆMORRHAGE.
}

By JAMES W. RUSSELL, M.A., M.D. CantaB., M.R.C.P. LOND.,

ASSISTANT PHYSICTAN TO THE BIRMINGHAM GENERAL HOSPITAL.

IN The LANCET of Jan. 28th, p. 222, I tried to discover whether any positive evidence could be obtained in favour of the suggested influence of variations in atmospheric pressure and temperature in determining the onset of cerebral hæmorrhage, with the result that in a series of 128 consecutive cases admitted into the Birmingham General Hospital five out of every nine were found to occur on days on which the barometric pressure was above the average. Temperature was not found to exercise any influence but a large preponderance of cases occurred on days on which a wind pressure below the average was recorded. In a letter to The LanceT of Feb. 4th, p. 322, Dr. W. H. Symons pointed out that the inequalities shown by my figures would be satisfactorily explained if there existed an actual preponderance of days of atmospheric pressure above the average in the years involved in the inquiry. This very obvious explanation had not occurred to me and on putting it to the test I find that it completely accounts for the excess of cases observed not only on days of high barometric pressure but also on days of low wind pressure. The point is not one of great importance, as the evidence obtained was at most inconclusive; but as my figures are, so far as I know, the only ones existing on the subject I feel bound to correct the inferences tentatively drawn from them. I have the less regret in doing so as my paper was not written with any desire to make out a case in favour of the suggested connexion, and that the present results are far more in accord with physiological probabilities.

In the 12 years under examination there were 4377 days on which the atmospheric pressure was above the average as compared with 2043 days when a pressure below the average was recorded. This preponderance of days of higher pressure would account for the occurrence of 68 out of my 128 cases on those days, leaving 60 for days of pressure below the average level. The actual numbers obtained were 71 and 57 respectively, and it therefore seems clear that the excess of cases occurring on days of higher pressure is entirely accounted for by the larger number of those days existing in the years under examination, and that my cases afford no evidence in favour of the suggested influence of high barometric pressure in causing cerebral hæmorrhage.

The figures obtained with regard to variations in pressure do not correspond quite so closely. On taking the pressure of each day in relation to that of the days preceding and following it, and using the same symbols as in my former paper, I get the following results :-

Actual number of days in the

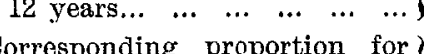

Actual distribution of cases as

published in former paper ...
128 cases

$$
\begin{aligned}
& <>\quad<\quad>< \\
& \begin{array}{lllllll}
988 & \ldots & 1148 & \ldots & 1176 & \ldots & 971
\end{array}
\end{aligned}
$$$$
\begin{array}{lllllll}
30 & \ldots & 34 & \ldots & 35 & \ldots & 29
\end{array}
$$$$
\begin{array}{lllllll}
29 & \ldots & 42 & \ldots & 28 & \ldots & 29
\end{array}
$$

It appears, therefore, that a small excess of cases occurred in the course of a steadily rising barometer beyond that accounted for by the preponderance of days with that arrangement. It is hardly, however, large enough to carry much weight as evidence of a causative effect.

In the matter of temperature the days are very evenly distributed as regards the average. Thus in the months concerned in one-third of the total number of the cases there were 334 days on which the temperature was above the average maximum for the month and 335 on which it was below the average. I did not, therefore, consider it worth while to continue the calculation, and the results of my former figures, which showed no causative effect of temperature, may be taken as correct. The apparent effects of a low wind pressure are similarly explained by the large excess of days with a pressure below the average. In the 12 years concerned there were 2973 days of low, as compared with 1343 days of high, pressure. This gives a distribution in 128 cases of 88 and 40 respectively. The actual figures obtained were 92 and 36, a sufficiently close approximation.

It thus seems to be established that actual height of barometric pressure, temperature, or wind pressure exercises no influence in determining the onset of attacks of cerebral hæmorrhage.

Birmingham.

\section{PLAGUE IN CATS.}

BY WILLTAM HUNTER, M.B., C.M. ABERD., GOVERNMENT BACTERIOLOGIST, HONG-KONG.

THE writings of past ages tell us that during epidemics of plague domestic pets were not spared the disease. It is only within recent years, however, that the occurrence of plague in animals such as cats, which are intimately associated with man, has attracted attention. In fact, until the question of rat plague was raised the presence of plague in animals was practically lost sight of and regarded of no significance in reference to the spread of the disease. With the knowledge of the presence of widespread rat plague and the fact that cats frequently devour these animals, the possible rôle plajed by cats in the dissemination of plague amongst human beings would appear to be of importance. Few accounts of natural plague infection in cats are to hand. The various plague commissions make mere mention of cat plague. They regard these animals as only slightly susceptible to the disease. In consequence they conclude that so far as the spread of plague is concerned cats are of no great importance.

Such an answer to the question of plague in cats is only partly true. Cats, when compared with many other animals, do appear relatively insusceptible. Their importance in the dissemination of plague, however, is underrated when the subject is viewed in the light of recent experience. The disease in cats is rare but the possibility of the occurrence of plague in domestic pets in plague-infected districts must not be forgotten. Experimentally produced plague in cats would appear to give inconstant results. The disease can be induced but much depends upon the method of incorporation of the virus. The German Plague Commission reported upon the effects of cutaneous and subcutaneous inoculation of these animals. Beyond a slight febrile reaction nothing definite was obtained. All the cats recovered. The commission concluded that cats were relatively insusceptible to plague. The results of Albrecht and Ghon were more definite. They fed cats on plague-infected material. Several of the animals died as the result of plague infection. The type of disease reproduced was septicæmic. In one or two instances a bubo was found in the submaxillary region. Kolle also fed cats with cultures of plague. Several of the animals died from plague. Wilm, in his report on plague, fed two cats with pieces of a plague bubo. The animals were sick for several days. Great emaciation of the cats was noted. Ultimately both animals recovered.

From these investigations on experimental plague infection in cats it is evident that infection per os gives the most constant results. By this method cats would appear to contract the disease. The question of a lethal termination probably depends upon the virulence of the infecting materia used for purposes of inducing the infection. As regards spontaneous plague infection in cats, extremely little would appear to be known. The Indian Plague Commission simply notes the fact and dismisses it in a sentence. In Sydney, Ashburton Thompson has reported the presence of plague infection in cats. He draws attention to the dangers attached to such a focus of infection.

An excellent opportunity of studying spontaneous plague infection in cats occurred recently in Hong-Kong. The history of the epizootic is the following. During the systematic collection of rats, dead and alive, in Kowloon for bacteriological examination many of those caught in the godowns were found to be plague infected. A week or two after rat plague had been found the servants of the Godown Company reported the death of several of their cats which were kept on the rat-infected premises. The bodies of these 
cats were sent to me for bacteriological examination. This was carried out as completely as possible, the morphological and cultural tests being typical of the bacillus pestis. The stalactite test was also positive. The cat mortality increased. I requested that all cats, sick or dead, should be forwarded to me. The sick cats were kept under observation in isolation. Experiments were made in regard to the modes of infection in cats and the symptoms of the disease were noted as carefully as possible. My investigations showed that cutaneous and subcutaneous inoculation do not give definite results. Feeding cats with plague buboes and pieces of human spleen crowded with plague bacilli give more or less constant results. The following experiments were undertaken.

Cat No. 1.-The animal was healthy and was kept under observation for at least 14 days. It was inoculated subcutaneously with one cubic centimetre of emulsion of plague bacilli on agar. After 24 hours the previously normal temperature rose to $102^{\circ} \mathrm{F}$. The animal refused food. A doughy swelling occupied the site of inoculation. After 72 hours, the temperature being $103^{\circ}$, the animal had vomiting and diarrhœa. 'The swelling was much the same in size but now felt boggy on palpation. No plague bacilli were found in the blood. From this time onwards, apart from a considerable loss in weight, the cat progressed favourably. The swelling developed into an abscess containing abund int staphylococci but no plague bacilli could be found.

Cat No. 2.-The conditions were the same as in No. 1. The animal was fed with the greater part of a large femoral bubo (human). On the next day the cat was decidedly ill. It refused food and suffered from watery diarrbœa. The temperature was $103^{\circ} \mathrm{F}$. From this time onwards the condition became aggravated; the temperature was irregular and maintained about $102^{\circ}-103^{\circ}$. The abdomen was distended and tender to touch. The diarrhoea continued to the last. No tenderness was noted in the axillæ or groins. Emaciation was also a marked feature. Death took place in seven days. The fæces were rubbed into the shaved abdomen of a guinea-pig. This animal died from plague in four days. A post-mortem examination was made. There was great congestion of all organs and tissues. Hæmorrhages of varying size were also found. The lymphatic glands were enlarged, red, and œdematous and on section showed marked cortical injection. There was no bubo. The intestinal mucous membrane showed great congestion, swelling, and slight erosion. Petechire were scattered throughout its entire length. The solitary follicles were enlarged and in some parts of the gut the condition resembled severe follicular enteritis. Plague bacilli were found throughout the body. The organism was isolated and subjected to the well-known tests.

Other experiments on healthy cats were not made owing to the number of cats from the godowns which I had at my disposal. From an observation of these animals I found that plague may be either acute or chronic. The following is a résumé of my results :-

Acute cat plague.-Symptoms: These are usually present within 24 hours. Food is refused. The hair of the animal becomes ruffled. Diarrhoea and vomiting are among the early symptoms. Weight is lost rapidly. The abdomen is distended and often tender to touch. Towards the end of the disease great weakness and even paralysis of the extremities are present. Death usually occurs in from two to six days.

Post-mortem appearances.-Bubonic swellings may be found, especially about the neck and the mesentery. The lymphatic glands in general are enlarged and show marked cortical injection. The general condition throughout the organs and tissues of the animal is one of extreme congestion and hæmorrhagic extravasation. The condition of the abdomen is interesting. The peritoneum is smooth and shiny. Very little fluid is present in the peritoneal cavity. Petechiæ may be found over the surface of the peritoneum. The stomach is congested, particularly on its mucous surface. The latter also shows the presence of innumerable hxmorrhages of varying size. No actual ante-mortem ulceration was found. The small intestine is in general reddened and little of engrossing interest was found until the ileum was reached. This part of the gut was the seat of many small hæmorrhages. The mucous surface was red and thickened. The latter was chiefly due to cedema. The solitary follicles were visible, being pin-head in size and greyish-yellow in colour. Small areas of necrosis were present; these appeared chiefly about the regions of hæmorrhagic extravasation. The mesenteric glands were enlarged. In one or two cases the appearance of distinct bubonic formation was found, the glands being matted together in hæmorrhagic extravasation, enlarged, with areas of necrosis, and containing myriads of plague bacilli. The type of disease was in all instances septicamic but special tendency was shown on the part of the plague bacilli to collect in the lymphatic apparatus.

Chronio cat plague.-The most prominent symptom is great emaciation. Buboes may be found in various situations of the body, especially about the neck. These are chronic in growth and are accompanied by a large amount of surrounding infiltration. These swellings break down ultimately, discharging thick creamy pus. The animals may live for two months. The condition is well described by the term "pest marasmus."

The following conclusions appear to be justified from the various observations and experiments on plague-infected cats. 1. Cats suffer from plague. 2. The disease may be acute or chronic. 3. The type of the disease is septicamic. 4. These animals may occasionally play a part in the dissemination of plague. 5. In plague-infected districts possible plague infection in cats is of great importance from a domestic point of view. 6. In plague-infected areas cats probably become infected through plague rats and mice which they devour as food.

Hong-Kong.

\section{SUPPURATIVE PERIOSTITIS FOLLOWING TYPHOID FEVER.}

By WILLIAM H. BATTLE, F.R.C.S. ENG., SURGEON TO ST. THOMAS'S HOSPITAL; AND

LEONARD S. DUDGEON, M.R.C.P. LOND.,

SUPERINTENDENT OF THE CLINICAL LABORATORY AND DEMONSTRATOR OF CLINICAL PATHOLOGX, ST. THOMAS'S HOSPITAI, ERASMUS

WILSON LECTURER, ROYAL COLLEGE OF SURGEONS OF ENGLAND.

THERE are now many instances of the occurrence of bone lesions after typhoid fever in the discharge from which the bacillus typhosus has been demonstrated. There are some unusual features in the following case which make it of exceptional interest. Most of those recorded have been affections of the tibir or ribs and the extent of bone involved has not been so extensive as here. It is unusual, also, to have an inflammatory attack of the bone which has arisen and subsided at a time when the bacilli would presumably be more active than at a later date. It is also noteworthy that although the periosteum was completely separated from the bone for some distance up the shaft and in the whole circumference the recovery of the limb without necrosis of bone has apparently been assured.

The patient was admitted into the Leopold ward of St. Thomas's Hospital on Oct. 28th, 1904, and was discharged on Dec. 21st, 1905. (The following is taken from the notes by Mr. Finch.) The patient was in the George ward, under the care of Dr. Hector W. G. Mackenzie, from July 7th to Sept. 10th, 1902, for typhoid fever. The illness had commenced on June 30th with headache, vomiting, and pain in the back and abdomen. On July 11th sym. ptoms of perforation developed at 1.30 P.M. Abdominal section was performed at 7.15 P.M. and a perforation of the ileum was sutured by Mr. Battle. The patient was readmitted on Sept. 18th for pain in the right femur and knee : this was treated with iodide of potassium and local applications and he was able to leave the hospital in about three weeks. Since that time he had remained well, but was readmitted some months after for pain in the abdomen which followed a slip whilst carrying a sack of coals. The present illness began four weeks before admission with pain in the lower half of the right femur. This pain was of a gnawing character, sometimes shooting down the leg; it was worse at night and kept the patient awake.

On admission the lower third of the right femur was uniformly enlarged and was extremely tender on pressure. The skin in front of the thigh in this situation was red from the application of mustard poultices before he came 